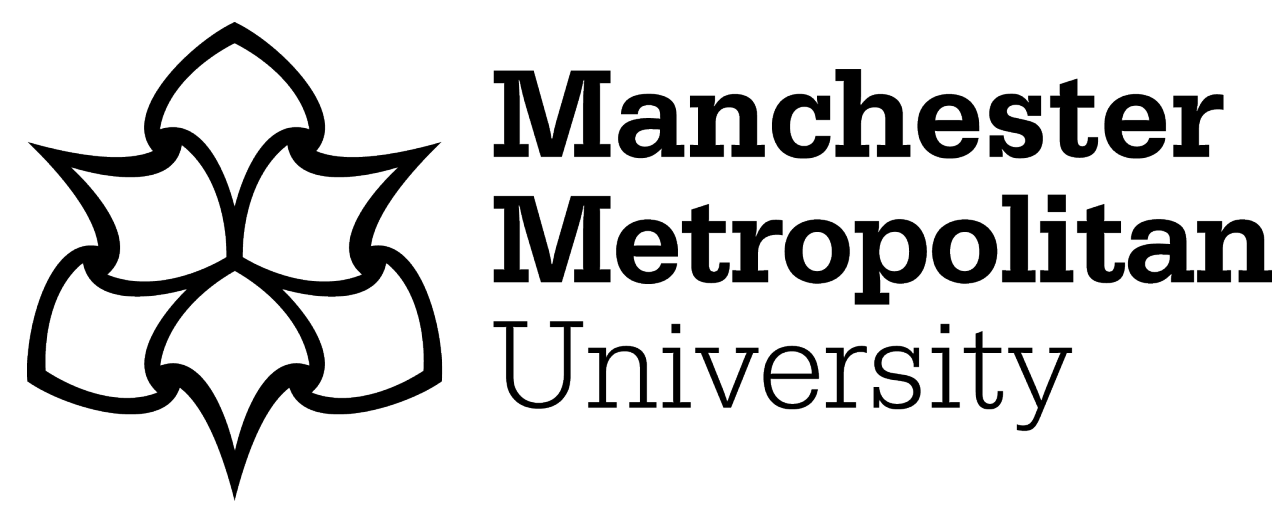

Wong, Phui Fung, Chia, Fah Choy, Kiu, Mee San and Lou, Eric CW ORCID logoORCID: https://orcid.org/0000-0001-7099-1426 (2022) Potential integration of blockchain technology into smart sustainable city (SSC) developments: a systematic review. Smart and Sustainable Built Environment, 11 (3). pp. 559-574. ISSN 2046-6099

Downloaded from: https: //e-space.mmu.ac.uk/626947/

Version: Accepted Version

Publisher: Emerald

DOI: https://doi.org/10.1108/sasbe-09-2020-0140

Usage rights: Creative Commons: Attribution-Noncommercial 4.0

Please cite the published version 


\title{
Potential integration of Blockchain technology into smart sustainable city (SSC) developments: A systematic review
}

\author{
Wong Phui Fung ${ }^{*}$, Chia Fah Choy ${ }^{1}$, Kiu Mee San ${ }^{1}$, Eric C.W. Lou ${ }^{2}$ \\ ${ }^{1}$ Department of Surveying, Lee Kong Chian Faculty of Engineering and Science, Universiti \\ Tunku Abdul Rahman (UTAR), Sungai Long Campus, 43000 Kajang, Malaysia. \\ 2 Department of Engineering, Manchester Metropolitan University, John Dalton Building, \\ Manchester M1 5GD, United Kingdom.
}

\section{Purpose}

Prior literatures lack of concrete and systematic review of the current blockchain application in smart sustainable city that covered to the full extent of various components. Thus, this study explores the integration of blockchain technology in making the city smarter, safer and sustainable.

\section{Design/methodology/approach}

This study conducted a systematic literature review of 49 publications published globally. Data were analysed by coding of the publications whereby the codes were generated based on frequency of appearance $(n)$.

\section{Findings}

The results showed that smart sustainable city could leverage blockchain technology in several areas such as governance, mobility, asset, utility, healthcare and logistics. Blockchain technology could also aid smart sustainable city in achieving social, environmental and economic sustainability.

\section{Originality/value}

This study proposes a smart sustainable city with blockchain technology framework: guiding city planners and policy makers by deploying blockchain that supports technology within smart sustainable city framework. This facilitates the digital transformation of a city toward smart and sustainable through the use of blockchain.

Keywords: Blockchain, decentralization, governance, mobility, smart city, smart sustainable city, sustainability.

\footnotetext{
*Corresponding author. Email: pfwong@utar.edu.my
} 


\section{Introduction}

Cities around the world is continuously changing and faced the most radical change in the past decades through the growing population rate due to urbanisation, demographic and social change, climate change, pollution and resource depletion. Cities are facing tremendous pressures as the United Nations (2018) predicted that two thirds of the world's population will be moving to cities by 2050, as compared to 55\% in 2018. Xie et al. (2019) further highlighted that the urbanisation level in developing countries Asia were at a high risk. The rapid increasing rate of urbanisation created various challenges and problems to a city such as environmental degradation, rising resources consumption, massive traffic congestion, air pollution due to increased carbon dioxide and greenhouse gas emissions (Silva et al., 2018). Resources are scarce - it is imperative to plan how to utilise the finite resources in the best possible way without compromising the capacity of future generations. Due to high density of population in urban areas, limited resources will be spread throughout the city, which could trigger food, water and/or resource crisis. All these problems create tremendous burden to a city and devise solutions for the sustainable development of cities while ensuring citizens' quality of life. Making a city smart is viewed as a novel solution to response to these problems to tackle smart cities' challenges.

Smart cities aim to improve quality of life of the citizens and build a sustainable urban environment by utilising advanced information and communication technologies (ICT) in city administration and services. There are several main goals of a smart city, such as engagement with citizens, increased openness of Government, better use of finite resources, effective management of traffic, improved environmental, health, and education services (Orecchini et al., 2018). ICT play a key role in the development of efficient infrastructures by using state-of-the-art technologies such as internet of things (IoT), artificial intelligence (AI), robotics, machine learning, big data processing and analytics tools, and cloud computing. Many devices and machines are connected with each other in a smart city, where large amount of data is created, shared, transferred, and stored. This scenario makes it difficult to manage devices and data by using traditional centralized approach (Xie et al., 2019). Blockchain is a promising technology to compliment smart city transformation due to its various features such as decentralisation, trust-free, transparency, security and immutable of transaction records, among others.

There were several studies regarding blockchain technology in smart sustainable city (SSC). Salha et al. (2019), Shen and Pena-Mora (2018), Bhushan et al. (2020) explained the use of blockchain technology in designing smart cities, and discussed the concepts, strengths, and weaknesses of blockchain technology. Several potential applications were provided such as governance, healthcare, energy, and supply chain but neglected other potential areas such as mobility and asset management. Orecchini et al. (2019) presented the possibility to integrate the blockchain technology in smart city, but particularly focus in smart environment and smart mobility. Nagel et al. (2019) proposed a business model of blockchain-based smart city applications after examining 80 start-ups' business models which offer products or services for smart cities. Xie et al. (2019) discussed how blockchain technology is applied in smart cities and when it should be used to solve the problems in smart cities. Gupta et al. (2020) proposed the use of blockchain to solve the inefficiencies of using conventional method for land record management systems. Similarly, Dewan and Singh (2020) focused of using the blockchain to buy, sell or rent a 
property in smart city. Besides, there were some reviews focused on the adoption of blockchain in one component only such as governance aspect (Pieroni et al., 2018), in energy trading (Andoni et al., 2019), in mobility (Jaffe et al., 2017), in supply chain (Cui et al., 2019), and in healthcare (Tanwar et al., 2020).

Although these papers discussed the application of blockchain in smart city, but the literature lacks of concrete and systematic review of the current blockchain application in SSC that covered to the full extent of smart components as a whole. Moreover, the connection of it with sustainability element is lacking in discussion. To fill this gap, this study aims to explore the stateof-the-art blockchain technology that could be applied in smart city developments and to achieve sustainability. This exploration can give policy makers and citizens, especially in a developing country, an overall and comprehensive understanding in which blockchain technology can provide critical support in the process of developing SSC. This could also help to achieve United Nations' sustainable development goals (SDGs) by leveraging blockchain technology in SSC.

\section{Smart Sustainable City (SSC) Development}

Smart city has become the spotlight for citizens and Governments - it was first introduced in 1994 and has been appeared frequently since 2010 (Ahvenniemi et al., 2017). A common definition provided by the European Commission (2012) is a smart city equips with the digital and advance technologies to regular city operations to improve living standards of their citizens, enhance quality of services provided, and making cities more sustainable. Marsal-Llacuna et al. (2015) highlighted that ICT plays a role in providing a better service to the citizens to improve quality of life, minimize and decrease environmental impact, and increase collaboration between both private and public sectors to stimulate economic growth which ultimately improved environmental, economic, and social sustainability for smart city. Yigitcanlar and Kamruzzaman (2018) highlighted cities' administration leverages smart technologies and systems to deal with current and future challenges in term of economic, social and environmental.

Silva et al. (2018) outlined that the four main attributes of a smart city were sustainability, quality of life, urbanisation and smartness. Sustainability is the key attributes of a city to balance the economics, social, and environmental aspects while performing city operations. It has been a key focus and major role in the emergence of smart cities. Most of the cities were facing resources constraints and it is crucial to scrutinise the scarcity of resources. Quality of life attributes concerns with the emotional and financial well-being of the city citizens. Ahvenniemi et al. (2017) summarised that people-oriented approach is important in smart city. The goals of smart cities were unable to achieve if without social commitment and awareness. This improvement could be done by innovative solution to encourage social learning and participation to enhance citizen's potential and capabilities in order to improve quality of life. Consequently, smart city will be equipped with competent citizens, which will benefit to the growth of a city. Urbanisation brought several challenges to a city such as resource scarcity, traffic congestion, pollution, and infrastructure obsolete. Thus, the city needs to focus on transformation in terms of technological, infrastructural, economical and governing aspects (Silva et al., 2018). Ultimately, it will manage the natural resources efficiently which in turn achieve sustainability. Smartness refers to the use 
of ICT or advanced technologies in city operation and administration to improve social, economic, and environmental performance of the city and its inhabitants. Deployment of technology is essential as a way to accelerate smart city adoption (Ahvenniemi et al., 2017).

\section{The Features of Blockchain Technology}

Blockchain has attracted widespread attention from various industries and sectors. It originates from Bitcoin, which was first introduced in 2008 as digital coin or cryptocurrency created by Satoshi Nakamoto (Shen and Pena-Mora, 2018). It is believed that it will be the next technological breakthrough that has great potential to innovate and improve every sectors and industries such as banking, healthcare, manufacturing and other industries. Blockchain utilises distributed ledger technology (DLT) across a network of users that relies on the consensus of a global peer network to function. The digital ledger is encrypted into a data structure called "blocks" and chained it to the previous block to form a linked chain. Blockchain can be classified into three types: public, private and federated blockchain based on control mechanism. In public blockchain, anyone have the full freedom to join the network and participate in the mining operation. Ethereum is an example of permission less blockchain system (Xie et al., 2019). The private or permissioned blockchain is a decentralised network whereby the data are shared with a group of people or organisation, thus, this type of blockchain is restricted to authorised entities to participate in the system. A federated or consortium blockchain is a partly private blockchain without a single owner organisation. Thus, the control is under authority of a group of companies or multiple organisations who are responsible for consensus and validation decisions. This type of blockchain is faster, higher scalability, and provide more privacy.

The key features of blockchain will drive and improve the SSC development (Ibba et al., 2017). Blockchain technology adopted decentralized system in peer-to-peer (P2P) network. Decentralization is a key feature of blockchain whereby the data recorded, stored, updated were distributed across all nodes in the distributed networks (Xie et al., 2019). Conventionally, many applications were operated in a centralized system which often inefficient due to single point of information capture, storage and analysis. Moreover, the transactions between seller and buyer will need a trusted intermediary to mediate the transactions which will slow down the process and incur additional cost. In blockchain, new information can be stored in addition to the past information in blocks while the centralized networks only allow the storing of the latest information at a time. Moreover, blockchain technology uses consensus algorithm to determine validity of block and which node could create it (Hakak et al., 2020). It refers to the rule and technique to ensure the participants to agree and process on the validity of the transactions. In blockchain, the consensus protocol validates the chronological and exact order of each transaction and information that were created, executed and modified (Aste et al., 2017). The quorum on nodes can be $51 \%$ of the nodes to allow consensus to occur prior a new block is appended to the shared ledger (Shen and Pena-Mora, 2018). The consensus on the chronological order is particularly important as it establishes ownership for digital assets and rights and obligations in the parties involved.

Immutability is one of the features of blockchain technology that made it in-favour with multiple industries (Ølnes et al., 2017). Transactions cannot be falsified, modified and deleted once it is chained into a block as each block (unique cryptographic number) contains a hash 
(cryptographic signature) of the block before. Blockchain records were also made irreversible and non-repudiable by virtue of one-way cryptographic hash function (Aste et al., 2017). The immutable trait also on account of the blockchain consensus protocol which require validation from the nodes of the blockchain network for any changes to the blocks. Any record is to be reserved permanently in blockchain unless more than $51 \%$ nodes take control to change at the time. Hence, the immutable blockchain ledger generates great trust-free platform, high reliability and security for the users. The breakthrough of blockchain technology 2.0 has allowed automation of digital contract using blockchain system which is called smart contract. Smart contract requires computerized transaction protocols and algorithms deployment to automate the execution of the term of contract. It consists a set of rules with the agreement terms which coded for autonomous execution in blockchain decentralized network - information about an agreement and will only be executed if the terms and conditions were verified by all nodes in the network and enforced by consensus protocol without centralized control (Scott, 2017).

\section{Research Methodology}

This research adopted systematic literature reviews as a means to search, filter, evaluate and interpret the available information relevant to a particular research topic. This method is appropriate for synthesise the existing literature (Petersen et al., 2008). A systematic literature review of the previous studies on the blockchain application in SSC was conducted for this research. The research process divided into four main stages which consist of identification of sources, filtering the relevant source, coding, and analysis of coding and aggregation as suggested by Dikert et al. (2016). Figure 1 summarised the process of conducting systematic literature review for this study.

Insert Figure 1 here

Firstly, keywords such as blockchain in smart city, SSC, sharing economy, smart concept, and smart application were used to search and identify the relevant sources from databases. Related academic journals, conference proceedings, articles and books that cover the blockchain use cases in SSC were examined. 466 publications were returned after searching in Science Direct database and IEEE Xplore. These publications were screened based on the titles whereby titles related to blockchain in fields other than SSC were excluded. Moreover, the screening process also involved abstract of the publication. The inclusion and exclusion criteria were used to filter the searched publication. The inclusion criteria were developed based on blockchain use cases in SSC. On the other hand, the exclusion criteria were publication with technical contents towards computer science or use cases not related to SSC. As a result, only 160 relevant publications remained.

The next stage is filtering the keywords and abstracts of these publications, only 49 relevant publications were selected for review. These selected publications were within the scope of this study, which is Blockchain technology used in SSC. Next, these relevant publications were extracted using Excel tabulation for systematic review and mapping process. Information including paper title, author(s), publication year, country of lead author, publication type, nature 
of publication, and research strategy were extracted and tabulated. The result is tabulated in table 1.

Based on Table 1, 65.4\% of the papers were journal papers, followed by $30.6 \%$ of conference papers, and only 1 from magazine and book series. In terms of year of publication, they were published between 2016 to 2020 . The largest numbers were $26.5 \%$ and $28.6 \%$ of the related paper published in 2018 and 2019 respectively. It was discovered that the "blockchain and SSC" topic has gained popular during the last five years. Table 1 revealed that geographical distribution of the selected papers. It demonstrated that selected paper related blockchain technology in SSC were across different countries, with majority from China (16.3\%), United States (14.4\%) and India (14.4\%). On the nature of study of the selected publications, 33 papers $(67.3 \%)$ were based on conceptual reasoning and literature review, whereas 16 papers $(33.3 \%)$ were empirical works. In the empirical works, 12 papers $(24.6 \%)$ were simulation, by 3 papers $(6.1 \%)$ were case studies and 1 paper adopted prototype design. This revealed that blockchain application in SSC is still at an exploratory stage. Future researches by using research methods such as simulation, case studies and prototype can be further considered. The top three Journals for the selected publications were Sustainable Cities and Society (6.3\%), Smart and Sustainable Built Environment and IEEE Access with 2 papers equally. The remaining of 42 papers were from various publishers, demonstrating that publication related blockchain application in smart city has gained the wide attention from various publishers.

\section{Insert Table 1 here}

Information from the publications were analysed by coding. This process was carried out by reading the relevant papers and this helps in defining a set of keywords and concepts which is representative to the research issue. Several codes were emerged from the coding process based on frequency of appearance $(n)$ in the selected papers. These codes included energy $(n=23)$, governance $(n=22)$, mobility $(n=19)$, public service $(n=18)$, healthcare $(n=17)$, transportation $(n=14)$ and more, as shown in Table 2. This showed that these areas have received attention in the research topic among the researchers. These codes were then synthesied by creating a higher category by adding new categories or merging and splitting existing categories. For instance, the codes of asset, building, property, real estate and built environment were merged into a main category which is smart asset. Energy, waste, water and carbon were grouped in smart utility. The codes of public services, voting and transportation are removed and the codes of governance and mobility are remained. Smart healthcare is formed through combining healthcare, safety and medicine. Lastly, smart logistic was created based on the code of logistic and supply chain. Six different categories are classified and formed that are as related to blockchain use cases in SSC displayed in Figure 2 and discussed further in the following section. 


\section{The Potentials of Applying Blockchain Technology in SSC}

Review process revealed that there were several potential application areas to integrate blockchain technology that could bring impact in developing a smart city, and at the same time to achieve better sustainability. These potentials were categorized into smart governance, smart mobility, smart asset, smart utility and smart logistics as illustrated in Figure 2. Among the six categories, the most frequently recurring topics in the areas of blockchain in SSC appear to be smart governance (25\%), smart mobility (20\%), smart utility (19\%) and smart healthcare (17\%); smart asset and smart logistic received less attention. It is suggested that future researches could focus on these components due to lack of discussion.

Insert Figure 2 here

\subsection{Smart Governance}

Blockchain technology could assist the Government in the governance of a smart city (Nagel et al., 2019). Government records such as tax revenues, donation funds, incomes, expenses, contracts, agreements can be recorded and interconnected via blockchain technology, which can keep an immutable and transparent record. This has several benefits such as improve transparency of public service delivery and operation, ensure document integrity, lowering administrative costs, and reducing corruption.

The electoral process could be benefit from the use of blockchain technology (Hakak et al., 2020). It could create a decentralised voting platform from election creation, voter registration, vote transaction, vote tallying, and vote verification, which eliminate manipulation of voting results. Xie at al. (2019) stated that vote records can be stored on blockchain which can avoid manipulation due to immutability features of blockchain. Ølnes et al. (2017) explained that a smart contract will ensure eligible citizen only cast a vote once and the identity of the voter can be accessed and stored securely based on blockchain. From this, blockchain can help create a secure, transparent and democratic voting system.

Blockchain could contribute within a smart city network in digital citizenships (Hakak et al., 2020). Citizens' personal data increases exponentially due to increasing population in smart city and storing these data securely become a challenging task to a city. In addition, verification of identity can be time-consuming and laborious which involve multiple layers and documents. However, citizen's identity and information such as national identity, birth and death registration, education and wedding certificates, passports, health and employment records can be tied to blockchain (Salha et al., 2019), which make it an ideal choice for data storage. These data and records remain encrypted and protected within the network. Furthermore, citizen can control the accessibility of their personal data. Where identity verification is required, data can be shared and authorised to be used by relevant parties and agencies - reducing fraud of using personal identities. Thus, citizen's privacy can be preserved by using blockchain chain in SSC (Hakak et al., 2020). This also expedites the identity detection and verification process without the need of a third party and various paper documents. 


\subsection{Smart Mobility}

Integrating blockchain in mobility and transportation is another intensive area of investigation (Ølnes et al., 2017). It aims to provide safe travel experiences for the drivers and passengers on the road, improve traffic condition and enhance conveniences in city transportation (Xie et al., 2019). The first area of application is vehicle data storage. The lifecycle of a vehicle typically lasts from 10-to-20 years; therefore, this information is important for the car industry. Blockchain creates a secured, trusted and decentralized platform to record and manage the vehicle data systematically to prevent frauds or illegal usage.

The growing of sharing economy and collaborative consumption brought problems such as trust issues. However, this could be solved by using blockchain that allows better personal data protection and ensuring privacy. For instance, ride sharing has become a common usage in sharing economy as mentioned by Shen and Pena-Mora (2018). A trusted network can be created when the information on the vehicle, driver, passengers are stored securely within blockchain network. The identities of the drivers and customers can be verified easily when engaging ride sharing services which will benefit both parties.

Silva et al. (2018) mentioned that conventional transportation system is not connected. Smart city requires revolutionary changes on these aspects by connecting all types of transportation mediums. As a result, a more efficient system for ticketing (e.g. planes, bus, trains, etc.) is required in smart city. A single platform offered by blockchain for the purchase of digital tickets and facilitating transactions by using digital tokens. Blockchain can be used as a single platform to store records and facilitating transactions for various types of transport mediums used in smart city. The uniformity of a single platform will ease the transaction and remove the hassle to visit multiple ticketing machines or desks.

An effective and highly trusted decentralized system is essential to manage large amounts of traffic and vehicle data to avoid a single point of failure. With that, blockchain can build a reliable, secure and distributed transport and vehicular management network (Xie et al., 2019). Traffic data such as road conditions and traffic congestions can be integrated with IoT sensors and blockchain. Real-time traffic data can be generated and accessed by city planners to monitor the traffic situations. For instance, instant alert messages could be notified in the event of traffic congestion or accidents. Alternative routes and transportation mediums could be proposed to the drivers and passengers based on real-time traffic data. By integrating blockchain in smart mobility, there is a potential for less vehicles on the road and traffic could be managed efficiently decreasing fossil fuel emission and air pollution.

Urban transportation sustainability is another aspect with large potential. Jaffe et al. (2017) suggested an incentive system that could be implemented by blockchain technology to motivate citizens in cycling to reward commuting habits. The reward system is also extended citizens taking shared rides or public transport in the smart city. This can be done by using digital tokens and the record can be stored at blockchain. Xie et al. (2019) proposed a blockchain incentive system to motivate vehicles to share road-related messages to manage traffic in real-time in smart cities. In addition, insufficient parking is a common issue in a city and Nagel et al. (2019) outlined that 
private households can make available house's grid by passing to the drivers for a parking fees, and this can be done via blockchain smart contracts.

\subsection{Smart Asset}

Blockchain can facilitate land, property/real estate, and housing registration and transaction (Rebrisoreanu et al., 2018) due to emergence of smart contracts. For example, in the property market, transaction details, owners' and buyers' details are centralized, where all participants have to rely on an authorized third party. With that, the buyer and seller need to pay service and management fees to the authorized third party which incur additional cost. The transaction process is lengthy and laborious which required various types of black and white documents for data verification and agreement. To overcome this, blockchain technology can used to build a decentralized data exchange platform and storage. Dewan and Singh (2020) created a blockchain network to buy, sell, or rent a property within smart city context that eliminating the need of centralized authority. It can facilitate users' identities verification, which replaces the traditional written agreement with intermediate. The property transaction details will be recorded immutably on the blockchain and this process is expedited since the removal of mediators in the process while ensuring cheaper and reliable transactions. Moreover, the problem of tenuous asset transaction, double-registry and frauds can be eliminated (Scott et al., 2017).

Blockchain can also assist in property development processes that include land registry, design, construction and maintenance stages. Rebrisoreanu et al. (2018) also outlined that blockchain technology could be used to manage land and property title registration to avoid fraud and corruption. Drawings, details, approvals, reports, and records can be captured and stored with the combination of blockchain and Building Information Modelling (BIM). This will bring accuracy in record keeping and transparency by providing an immutable view throughout the lifecycle of an asset. Future maintenance and timely repairs can be managed effectively for facilities management as records can be accessed easily through blockchain. Salha et al. (2019) also explained that smart contracts can be initiated automatic payments upon completion of works by builders or material orders. The problem of late payments that often lead to disputes between the client and main builder could be eliminated or reduced significantly.

\subsection{Smart Utility}

There are several ways that blockchain technology will assist in smart utility, with the first application area in energy management system (Orecchini et al., 2018). Blockchain will assist in recording energy usage and demand securely and accurately to ensure data integrity and accuracy. Smart Energy Grids was proposed by Pieroni et al. (2018) based on blockchain technology by connecting several devices and equipment to energy accumulator via networks and an app (Blockchain_SEG App) via mobile to reach the trading platform. Energy amount stored in the accumulators and actual energy consumption could be tracked easily using blockchain. Manual readings will be obsolete (Nagel et al., 2019) as blockchain guarantees data integrity and collection simplicity. The consumers will be aware of their consumption patterns and feeding need which allow them to react accordingly. Similarly, blockchain technology can be used to monitor water consumption level to regulate water usage for different areas in the city. 
Most of the electricity energy produced from fossil energy have adverse effects to the environment. Renewable energies, such as solar, needs to use more widely and blockchain enables peer-to-peer energy transaction (Bhushan et al., 2020). Prosumers will be able to convert their surplus energy into tokens and sell-on to other consumers in a decentralized approach. For instance, prosumers with solar panels could sell excess energy to neighbours on the same road, which then minimises energy loss (Pieroni et al., 2018). A transaction occurs and will be recorded in the blockchain ledger when prosumers decide to sell and consumers decide to buy energy. The payment is conducted automatically through energy trading via smart contracts deployed on the blockchain. Thus, it creates a decentralised energy market by initiating transaction and payments between consumers and buyers without the need of intermediates.

Effective waste management is crucial for the sustainability of a smart city due to urbanisation which increases waste generation (Silva et al., 2018). Blockchain could be integrated with IoT sensors and AI in waste management operations from waste collection, disposal, recycle and/or recovery. For instance, IoT sensors will detect waste accumulation of households and alert waste collection operators to collect and dispose the waste. This information can be stored on the blockchain and shared to the users and relevant parties. Owing to real-time tracking capabilities, it helps to optimise waste collecting schedules and optimum routes for collection; and also helps to ensure maximum utilization of fuel by waste collection trucks since collection schedules can be planned properly.

In addition, blockchain technology can also be used to track carbon footprints of home appliances, goods, tools, vehicles and equipment (Shen and Pena-Mora, 2018). Manufacturers, suppliers and consumers will be able to better understand environmental impacts of each products to improve carbon emission compliance. The carbon footprints can be recorded in blockchain based application to determine the charges of carbon tax, where applicable. This would discourage potential buyers from purchasing where the carbon tax charges are high, which subsequently reducing the products' demand. Blockchain based system can monitor environmental quality in a city, where environmental data could be integrated with IoT sensors and linked to blockchain to alert citizens on the air quality index (Ibba et al., 2017). The levels of pollutants could be measured for monitoring purposes in order to devise better efficient ways to combat pollution before the pollution issue escalates. Thus, it also helps to maintain a healthy environment for the city.

\subsection{Smart Logistics}

A transparent, decentralized and trusted supply chain management can be established by blockchain to facilitate track-and-trace (Li et al., 2018). Supply chain of products and services consist of a myriad of entities that involve in different stages such as design, manufacture, deliver and sales. Most products are not produced by a single company, but a chain of suppliers that are composed of manufacturers and service providers which make the supply chain complex. Most importantly, these entities (e.g., manufactures, distributors, transporters, suppliers and retailer) have very little knowledge about the details of the life cycle of a product (Xie et al., 2019). On the other hand, the consumer also has little information on the supply chain of the products which jeopardize their trusts on a product and service they purchase. Thus, a decentralised, transparent and trusted information sharing platform is needed to store supply chain information. A 
blockchain-based system can be used to store information and shared among the entities along the supply chains. Based on the information, entities can predict market trends and optimise their decision-making process (Bhushan et al., 2020). Consumers can also easily verify the authenticity of the product which will gain trust on the product. The blockchain technology can guarantee the reliability of the shared information which create responsibility and sustainability in sourcing and production. Hence, supply chain management can be improved by using blockchain.

Improving product traceability is a growing concern in a smart city. Blockchain application can help in tracking provenance of each products along the supply chain due to transparency features. It provides an immutable record on the state of a product from mining, extraction, production, transportation and in use. Thus, it streamlines the operation of the supply chain with complete information and prevent counterfeit products in the market as it provides a tamper-proof tracing record. Blockchain technology has a great potential in agricultural and food traceability (Xie et al., 2017) to ensure food safety and quality. It helps to pinpoint the source easily in the event of contamination by tracing the products' origin in the blockchain system. It can trace the entire supply chain process in real-time by removing the need for multiple verification by different parties. In this way, the sources of problem can easily identify.

\subsection{Smart Healthcare}

Blockchain could potentially help in improving healthcare industry (Bhushan et al., 2020) as conventional medical systems are insufficient to cope with the exponential growth of healthcare demand for smart cities. With rapid growth of urban population, large amount of medical data is generated and stored - data are important for treatment decisions. Conventionally, patients' medical records are scattered across different places such as hospitals, clinics, medical centres or other healthcare providers. There is no central place to store these data completely which resulted difficult to trace the patients' complete medical history and it affects the treatment of patients. However, patients' medical data can be stored securely and immutably in the blockchain (Nagel et al., 2019).

Medical patients can use blockchain to specify the accessibility of their medical data (Xie et al., 2019). Blockchain offers a secure framework for the patients to control their data accessibility and protect their privacy. With the permission from patients, data can only be accessible to authorised parties and healthcare organisations by preventing unauthorized manipulation. For instance, the patient can give the accessibility to other healthcare organisations who may not have a complete history and record of the patient's health. By storing health data in blockchain, the current healthcare organisation could view the diagnosis notes from previous healthcare organisations as this is critical for the efficient treatment of patients. In addition, it allows the doctors to make real time decisions with the real time information even in a remote place. Moreover, it can also help streamline the processes associated with medical insurance claims. The insurance industry involves several layers of intermediaries which make a frustrating approval process (Salha et al., 2019). With the ease of patient's data access via blockchain, the speed of approval will be increased by eliminating the intermediaries.

Blockchain could be used to monitor and track the pharmaceutical supply chains to prevent counterfeits and illegal trading (Xie et al., 2019). Fabrications throughout the supply chain to the 
end consumers could be registered in the blockchain network. The origin of the medicines can be tracked and traced easily by logging time series transaction data generated by IoT sensors to a blockchain for verifiability. Nagel et al. (2019) also suggested the use of HealthCoin to reward health conscious citizens to ensure a good lifestyle and behaviours.

\section{Discussion}

The findings from the review demonstrated that blockchain could assist cities in term of governance, asset, mobility, utility, logistics and healthcare. The key features of blockchain such as decentralize, transparent, secure, immutable and distributed make it as an opportunity to improve potentialities of SSC development. By leveraging blockchain, cities will be in a better position to achieve sustainability targets in environmental, social, and economic aspects - the triple bottom line of sustainability development. In tandem, this could assist the Country's commitment in achieving SDGs as urged by the United Nations. This study revealed that blockchain applications in SSC can enhance social aspects focuses on people in well-being, health and safety. Aghimien et al. (2020) discovered that lack of citizen participation, poor governance due to lack of trust and fear of potential system failure are the challenges hindering the SSC development. This could be achieved through schemes such as digital administration and citizenships, smart health records, medicine and food supply chain to ensure safety by leveraging blockchain technology as it ensures a transparent, tamper-proof and secure systems as compared to conventional system. In economic aspects, a large number of applications focusing on sharing economy, collaborative consumption, and other related areas to improve income such as smart governance, smart mobility, smart utility and smart logistic, aiming to bring significant impact to both businesses and consumers, potentially contributing to economic boost. For instance, blockchain have enabled applications of sharing economy in the energy sector through energy trading and transportation sector via car sharing which improve asset utilization, monetise citizens' assets and generate extra incomes to tackle unemployment issue (Andoni et al., 2019). Besides, removing intermediaries and improving supply chain management in smart logistic could streamline the business processes in many sectors which contributing to the economic sector (Shen and Pena-Mora, 2018).

Concentration of population in cities has triggered many problems as explained by Aghimien et al. (2020) and the goals of smart cities were to optimise the use of limited resources, reducing waste and improving air quality by safeguarding the environment (Orecchini et al., 2018). Within the environmental aspect, blockchain applications have concentrated on smart utilities and smart mobility within smart city to promote greater awareness of city health (Silva et al., 2018). Large numbers of blockchain use cases concerning the energy sector to better use of energy through P2P energy transaction which reduce reliant of non-renewable resources. Proper water and waste management, air quality and carbon emission monitoring have also been covered with the use of blockchain in SSC to safeguard these finite resources. Besides, integrating blockchain in transportation system such as transportation sharing and incentive system to motivate vehicle sharing or share road-related message will further enhance the quality of life of citizens while ensuring city's environmental sustainability (Silva et al., 2018; Shen and Pena-Mora, 2018).

Despite the potentials of blockchain in smart sustainable city, the technology exhibits numerous challenges that need to be addressed. The first issue is the data security and privacy. 
Shen and Pena-Mora (2018) outlined a few security risks associated with blockchain-based system such as double spending by malicious party and owning $51 \%$ of the computing power would compromise the system. Blockchain technology ensures transactions transparency, therefore information from sender, receiver, amount, and other complete information will be visible by the blockchain network participants. As a result, the user's activities can be traced and tracked by the node in the network. This maybe a limitation for use cases where privacy is a necessity. Xie et al. (2019) further highlighted the cost of deploying a blockchain-based system in smart sustainable city is one of the main issues during implementation and it remains unknown. The operation and maintenance cost of blockchain system remains a big issue within a smart sustainable city which required further empirical study. Legal and regulatory issues need to be addressed for blockchainbased system in smart sustainable city (Salha et al., 2019). Unlike traditional centralised systems, Blockchain adopted a decentralized system without intermediary, hence a new set of regulation is required to suit for it to avoid disputes among the parties. Moreover, large quantity of data with different formats will be generated by various devices in smart sustainable cities and be processed by blockchain technology. The data format and storage standards need to be considered as well to ensure data can be exchanged seamless and interoperability challenges can be solved.

Scalability is another issue and it refers to number of transactions in each block and its interval time. As an example, the average time required to verify Bitcoin transactions take 10 minutes or longer to process, and with the maximum of 7 transactions per second (Xie et al., 2019). However, in contrast, Visa which is the mainstream payment processor can process an average of 2,000 transactions per second and up to 56,000 transactions per second if required (Gilbert, 2016) while PayPal can transact 10 million transactions per day. It clearly shows that there is a big gap in scalability between Bitcoin and the mainstream payment processors. Therefore, proper schemes need to be designed to improve the scalability of blockchain systems to support billions of devices and huge volumes of transactions within smart sustainable city. Salha et al. (2019) described that blockchain technology is energy intensive. Proof of work (PoW) is one of the common consensus algorithms used in blockchain network and this mechanism has several limitations such as it consumes large amount of electrical energy and computationally expensive (Bhushan et al., 2020). It contradicts with the goal of smart city in achieving energy efficiency. Thus, an alternative of consensus mechanism is required to propose to address the issues of high energy consumption, expensive, and scalability limitation.

Notwithstanding the limitations of blockchain technology, there are tremendous potential of using blockchain in SSC. This study reinforces that blockchain can accelerate SSC adoption in achieving sustainability goals. A framework was proposed to facilitate understanding of applying blockchain in SSC as presented in Figure 3. This will be helpful to incorporate blockchain application into future smart city planning and development by assisting urban city planners, policy makers, industrial practitioners and stakeholders especially developing countries to make informed decisions, take appropriate actions, and plan for cities' development towards a smarter and more sustainable city. Smart city development is an expensive investment and is crucial for responsible parties to understand that the concepts of smart and sustainability should be aligned (Yigitcanlar and Kamruzzaman, 2018) during planning and formation of SSC before heavily investing on it. Next, the proposed framework contributes a list of potential application in using blockchain at SSC in body of literature. This can improve the understanding on how blockchain could fit in the SSC in various smart components. Future studies can look into the evaluation the 
applicability and importance of blockchain technology in specific use cases by focusing on smart asset and smart logistic. Further empirical studies on the relationship between city smartness and sustainability could be investigated.

Insert Figure 3 here

\section{Conclusion}

The world has experienced unprecedented growth due to population increase that added immense pressure on the existing city's infrastructure and resources. The city also faces numerous problems such as traffic congestion, global warming, climate change, limited resources - leading it to be unable to cope with the need of high population. SSC is seen as key solution to address these challenges with emerging advanced technologies such as blockchain. This study aims to explore the potential application of blockchain in accelerating the development of SSC. The findings of this study revealed that blockchain technology could assist SSC in achieving social, environmental, and economic sustainability. Thus, there is a strong alignment of blockchain technology with SDGs, where this implementation can assist in attaining SDGs within SSC development. SSC could leverage blockchain technology in several aspects such as governance, mobility, logistics, utilities, healthcare, and assets. A smart sustainable city-blockchain (SSCB) integration framework was proposed as the outcome of this study. Future studies could seek opinion on large population to uncover the citizen's perception on SSC development by integrating blockchain technology. It serves a guidance and framework for city planners, local authorities and regulators to design appropriate public policies in deploying blockchain technology in developing SSC. It enables target setting for a city on future direction based on citizens' opinion so that assessment can be conducted to assess whether the development is proceeding towards the wanted direction.

\section{References}

Aghimien, D. O., Aigbavboa, C., Edwards, D. J., Mahamadu, A. M., Olomolaiye, P., Nash, H., and Onyia, M. (2020), "A fuzzy synthetic evaluation of the challenges of smart city development in developing countries", Smart and Sustainable Built Environment, Vol. aheadof-print, doi: 10.1108/SASBE-06-2020-0092

Ahvenniemi, H., Huovila, A., Pinto-Seppä, I., and Airaksinen, M. (2017), "What are the differences between sustainable and smart cities?", Cities, Vol. 60, pp. 234-245, doi: 10.1016/j.cities.2016.09.009

Andoni, M., Robu, V., Flynn, D., Abram, S., Geach, D., Jenkins, D., McCallum, P. and Peacock, A. (2019), "Blockchain technology in the energy sector: A systematic review of challenges and opportunities", Renewable and Sustainable Energy Reviews, Vol. 100, pp.143-174, doi: 10.1016/j.rser.2018.10.014 
Aste, T., Tasca, P., and Di Matteo, T. (2017), "Blockchain Technologies: The Foreseeable Impact on Society and Industry", Computer (Long. Beach. Calif), Vol. 50 No. 9, pp. 18-28, available at: https://discovery.ucl.ac.uk/id/eprint/10043048/1/Aste_BlockchainIEEE_

600W_v3.3_A.doccceptedVersion.x.pdf (accessed 19 September 2019)

Bhushan, B., Khamparia, A., Sagayam, K.M., Sharma, S.K., Ahad, M.A. and Debnath, N.C. (2020), "Blockchain for smart cities: A review of architectures, integration trends and future research directions", Sustainable Cities and Society, Vol. 61, pp.102360, doi: 10.1016/j.scs.2020.102360

Cui, P., Dixon, J., Guin, U. and Dimase, D. (2019), “A Blockchain-Based Framework for Supply Chain Provenance", IEEE Access, Vol. 7, pp.157113-157125, doi: 10.1109/ACCESS.2019.2949951

Dewan, S. and Singh, L. (2020), "Use of blockchain in designing smart city," Smart and Sustainable Built Environment, Vol. ahead-of-print, doi:10.1108/SASBE-06-2019-0078

Dikert, K., Paasivaara, M., and Lassenius, C. (2016), "Challenges and success factors for largescale agile transformations: A systematic literature review," Journal of Systems and Software, Vol. 119, pp. 87-108, doi: 10.1016/j.jss.2016.06.013

European Commission. (2012), "Communication from the commission. Smart cities and communities- European innovation partnership. Brussels", available at: http://ec.europa.eu/energy/technology/initiatives/doc/2012_4701_smart_cities_en.pdf (accessed 12 October 2019)

Gilbert, D. (2016), "Bitcoin's Big Problem: Transaction Delays Renew Blockchain Debate", International Business Times, available at: http://www.ibtimes.com/bitcoins-bigproblemtransaction-delays-renew-blockchaindebate-2330143 (accessed 10 April 2020)

Gupta, R., Shah, M. N., and Mandal, S. N. (2020), "Emerging paradigm for land records in India", Smart and Sustainable Built Environment, Vol. ahead-of-print, doi: 10.1108/SASBE-112019-0152

Hakak, S., Khan, W.Z., Gilkar, G.A., Imran, M. and Guizani, N. (2020), "Securing smart cities through blockchain technology: Architecture, requirements, and challenges", IEEE Network, Vol. 34 No. 1, pp. 8-14, doi: 10.1109/MNET.001.1900178

Ibba, S., Pinna, A., Seu, M., and Pani, F. E. (2017), "CitySense: blockchain-oriented smart cities", Proceedings of the XP2017 Scientific Workshops, May 22 - 26, pp. 1-5, Cologne Germany, doi:10.1145/3120459.3120472

Jaffe, C., Mata, C., and Kamvar, S. (2017), "Motivating urban cycling through a blockchain-based financial incentives system", ACM International Joint Conference on Pervasive and Ubiquitous Computing and Proceedings of the 2017 ACM International Symposium on Wearable Computers, pp. 81-84, doi: 10.1145/3123024.3123141 
Li, J., Greenwood, D. and Kassem, M. (2018), "Blockchain in the built environment: analysing current applications and developing an emergent framework", Creative Construction Conference, Ljubljana, Slovenia, June 20 - July 3, available at: http://nrl.northumbria.ac.uk/id/eprint/34633

Marsal-Llacuna, M. L., Colomer-Llinàs, J., and Meléndez-Frigola, J. (2015), "Lessons in urban monitoring taken from sustainable and livable cities to better address the Smart Cities initiative", Technological Forecasting and Social Change, Vol. 90, pp. 611-622, doi: 10.1016/j.techfore.2014.01.012

Nagel, E., Kranz, J., Sandner, P., and Hopf, S. (2019), "How Blockchain Facilitates Smart City Applications-Development of a Multi-Layer Taxonomy", Twenty-Seventh European Conference on Information Systems (ECIS2019), Stockholm-Uppsala, Sweden, 8-14 June, pp. 1-17, available at: https://aisel.aisnet.org/ecis2019_rp/103

Ølnes, S., Ubacht, J., and Janssen, M. (2017), "Blockchain in government: Benefits and implications of distributed ledger technology for information sharing", Government Information Quarterly, Vol. 34, pp. 355-364, doi: 10.1016/j.giq.2017.09.007

Orecchini, F., Santiangeli, A., Zuccari, F., Pieroni, A. and Suppa, T. (2018), "Blockchain Technology in Smart City: A New Opportunity for Smart Environment and Smart Mobility", In: Vasant, P., Zelinka, I., Weber, G. W. (eds), Intelligent Computing \& Optimization. ICO 2018. Advances in Intelligent Systems and Computing, Springer, Cham, Vol. 866, pp. 346354, doi: 10.1007/978-3-030-00979-3_36

Petersen, K., Feldt, R., Mujtaba, S., \& Mattsson, M. (2008), "Systematic mapping studies in software engineering", 12th International Conference on Evaluation and Assessment in Software Engineering (EASE), Vol. 12, pp. 1-10, doi: 10.14236/ewic/EASE2008.8

Pieroni, A., Scarpato, N., Di Nunzio. L., Fallucchi, F. and Raso, M. (2018), "Smarter city: smart energy grid based on blockchain technology", Int J Adv Sci Eng Inf Technol. Vol. 8 No. 1, pp. 298-306, doi: 10.18517/ijaseit.8.1.4954

Rebrisoreanu, M., Rus, C., Leba, M., and Ionica, A. (2018), "Exploring the Possibilities of Blockchain Use in a Smart City", International Journal of Systems Applications, Engineering \& Development, Vol. 12, pp. 164-167, available at: https://www.naun.org/main/UPress/saed/2018/a562014-aca.pdf

Salha, R. A., El-Hallaq, M. A., and Alastal, A. I. (2019), "Blockchain in Smart Cities: Exploring Possibilities in Terms of Opportunities and Challenges", Journal of Data Analysis and Information Processing, Vol. 7 No, 3, pp 118-139, doi: 10.4236/jdaip.2019.73008

Scott, B., Loonam, J., and Kumar V. (2017), "Exploring the rise of blockchain technology: Towards distributed collaborative organizations", Strategic Change, Vol. 26 No. 5, pp. $423-$ 428, doi: $10.1002 /$ jsc. 2142 
Shen, C., and Pena-Mora, F. (2018), "Blockchain for cities - a systematic literature review", IEEE Access, Vol. 6, pp. 76787-76819, doi: 10.1109/ACCESS.2018.2880744

Silva, B. N., Khan, M. and Han, K. (2018), "Towards sustainable smart cities: A review of trends, architectures, components, and open challenges in smart cities", Sustain Cities and Society, Vol. 38, pp. 697-713, doi: 10.1016/j.scs.2018.01.053

Tanwar, S., Parekh, K. and Evans, R. (2020), "Blockchain-based electronic healthcare record system for healthcare 4.0 applications", Journal of Information Security and Applications, Vol. 50, pp.102407, doi: /10.1016/j.jisa.2019.102407

United Nations. (2018), "World Urbanisation Prospects", available at: https://esa.un.org/unpd/wup/ (accessed 25 October 2019)

Xie, C., Sun, Y., and Luo, H. (2017), "Secured data storage scheme based on block chain for agricultural products tracking", 3rd International Conference on Big Data Computing and Communications (BIGCOM), August 10 - 11, Chengdu, China, pp. 45-50, doi: 10.1109/BIGCOM.2017.43

Xie, J., Tang, H., Huang, T., Yu, F. R., Xie, R., Liu, J., and Liu, Y. (2019), “A survey of blockchain technology applied to smart cities: Research issues and challenges", IEEE Communications Surveys \& Tutorials, Vol. 21 No. 3, pp. 2794-2830, doi: 10.1109/COMST.2019.2899617

Yigitcanlar, T., and Kamruzzaman, M. (2018), "Does smart city policy lead to sustainability of cities?", Land Use Policy, Vol. 73, pp. 49-58, doi: 10.1016/j.landusepol.2018.01.034 


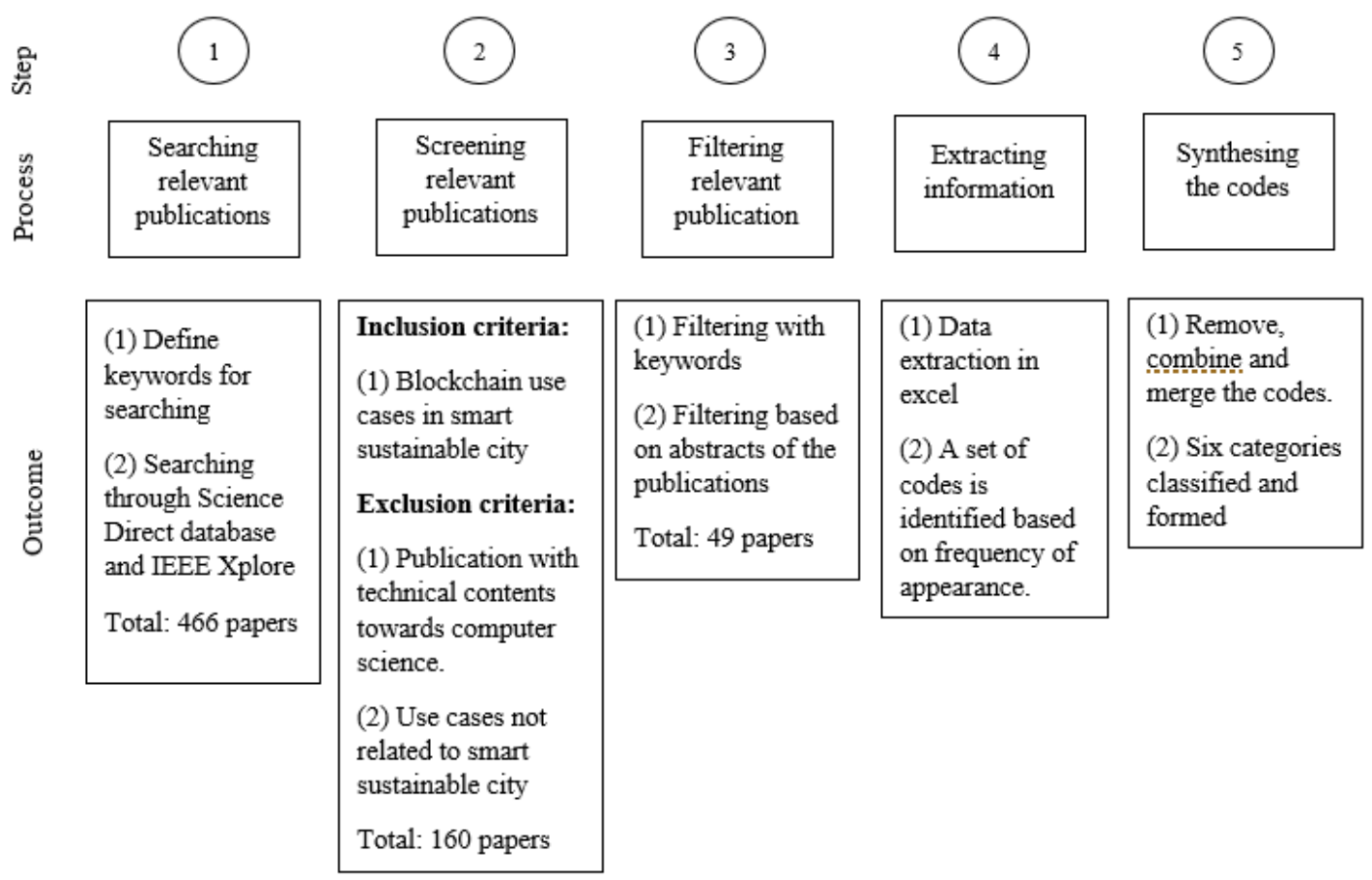

Figure 1: Systematic review process 


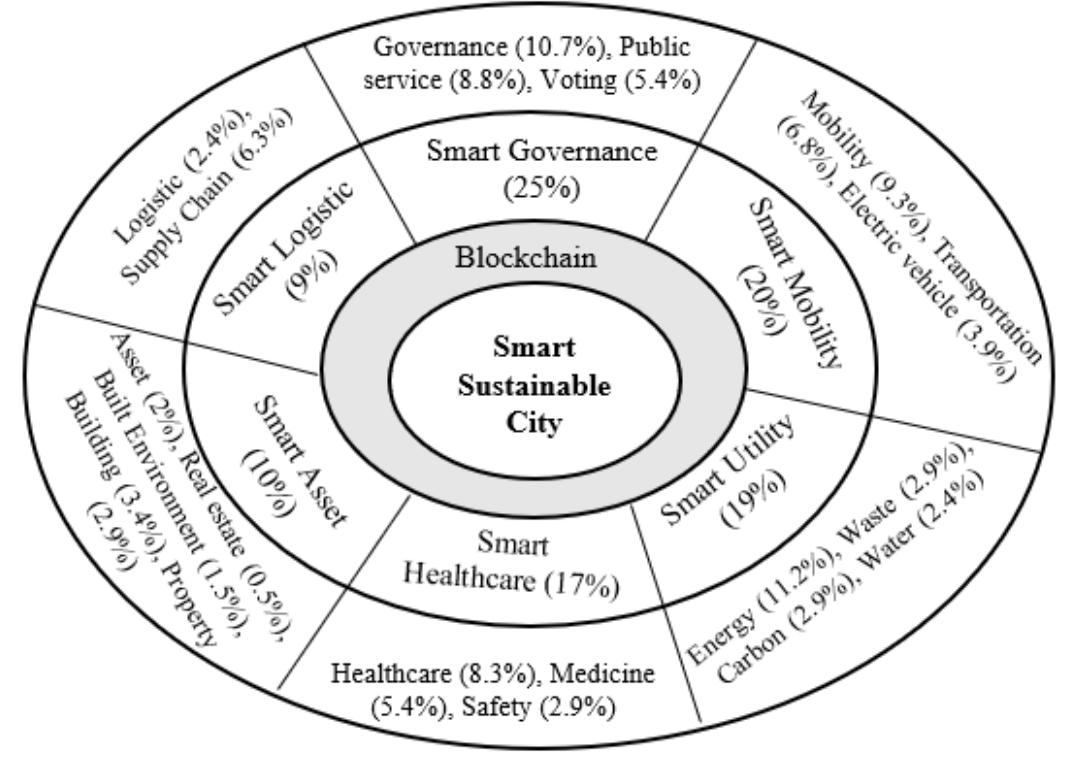

Figure 2: Blockchain application area in smart sustainable city

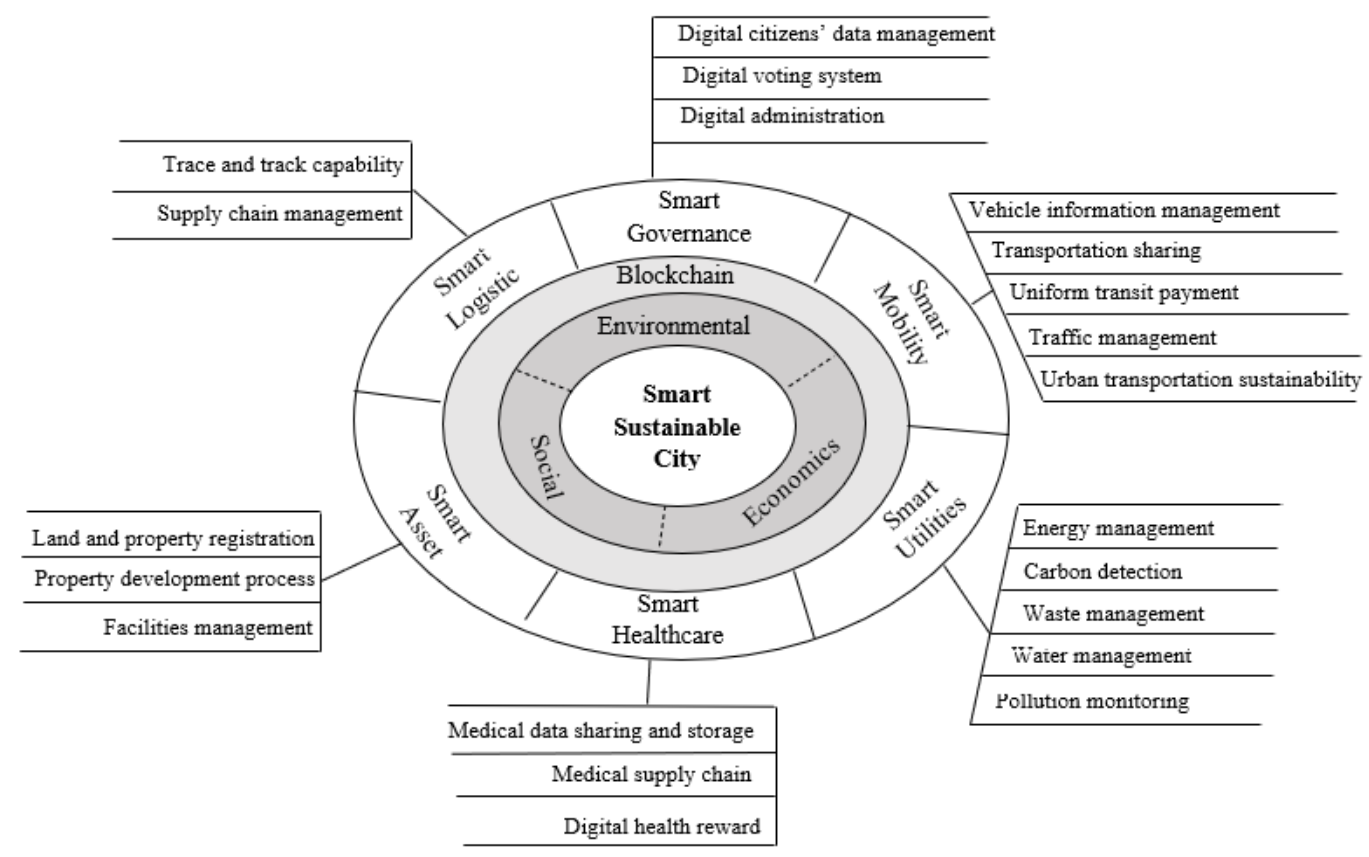

Figure 3: Smart sustainable city-blockchain (SSCB) integration framework 
Table 1 Information of selected reviewed papers

\begin{tabular}{|c|c|c|c|c|c|}
\hline & $\begin{array}{l}\text { Number } \\
\text { (n) }\end{array}$ & $\begin{array}{l}\text { Percentage } \\
(\%)\end{array}$ & & $\begin{array}{l}\text { Number } \\
(\mathrm{n})\end{array}$ & $\begin{array}{c}\text { Percentage } \\
(\%)\end{array}$ \\
\hline \multicolumn{3}{|c|}{ Type of publications } & \multicolumn{3}{|c|}{ Geographical distribution of publications } \\
\hline Journal & 32 & 65.4 & China & 8 & 16.3 \\
\hline Conference & 15 & 30.6 & United State (US) & 7 & 14.4 \\
\hline Magazine & 1 & 2.0 & India & 7 & 14.4 \\
\hline \multirow[t]{3}{*}{ Book series } & 1 & 2.0 & Italy & 4 & 8.3 \\
\hline & & & $\begin{array}{l}\text { United Kingdom } \\
\text { (UK) } \\
\text { United Arab }\end{array}$ & 3 & 6.1 \\
\hline & & & Emirates (UAE) & 2 & 4.1 \\
\hline \multicolumn{3}{|c|}{ Year of publications } & Romania & 2 & 4.1 \\
\hline 2016 & 6 & 12.3 & Korea & 2 & 4.1 \\
\hline 2017 & 8 & 16.3 & Brazil & 2 & 4.1 \\
\hline 2018 & 13 & 26.5 & Austria & 2 & 4.1 \\
\hline 2019 & 14 & 28.6 & Greece & 1 & 2.0 \\
\hline \multirow[t]{2}{*}{2020} & 8 & 16.3 & Gaza, Palestine & 1 & 2.0 \\
\hline & & & Morocco & 1 & 2.0 \\
\hline \multicolumn{3}{|c|}{ Nature of the publications } & Spain & 1 & 2.0 \\
\hline Conceptual & 33 & 67.3 & Germany & 1 & 2.0 \\
\hline Simulation & 12 & 24.6 & Norway & 1 & 2.0 \\
\hline Case study & 3 & 6.1 & Jordan & 1 & 2.0 \\
\hline \multirow[t]{2}{*}{ Prototype } & 1 & 2.0 & Australia & 1 & 2.0 \\
\hline & & & Finland & 1 & 2.0 \\
\hline \multicolumn{3}{|l|}{ Top 3 Journals } & Poland & 1 & 2.0 \\
\hline $\begin{array}{l}\text { Sustainable Cities } \\
\text { and Society }\end{array}$ & 3 & 6.1 & & & \\
\hline IEEE Access & 2 & 4.1 & & & \\
\hline Smart and & 2 & 4.1 & & & \\
\hline \multicolumn{6}{|l|}{ Sustainable Built } \\
\hline Environment & & & & & \\
\hline
\end{tabular}


Table 2 List of codes

\begin{tabular}{lc|lc}
\hline \multicolumn{1}{c|}{ Codes } & $\begin{array}{c}\text { Number of } \\
\text { frequency (n) }\end{array}$ & \multicolumn{1}{c}{ Codes } & $\begin{array}{c}\text { Number of } \\
\text { frequency (n) }\end{array}$ \\
\hline Governance & 22 & Waste & 6 \\
Public Service & 18 & Water & 5 \\
Voting & 11 & Carbon & 6 \\
Mobility & 19 & Logistic & 5 \\
Transportation & 14 & Supply chain & 13 \\
Electric vehicle & 8 & Asset & 4 \\
Healthcare & 17 & Built Environment & 3 \\
Safety & 6 & Building & 7 \\
Medicine & 11 & Property & 6 \\
Energy & 23 & Real estate & 1 \\
\hline
\end{tabular}

